\title{
Increasing User Satisfaction of Mobile Commerce using Usability
}

\author{
Ninyikiriza Deborah Lynn ${ }^{1}$ \\ Magister Informatika \\ Universitas Atma Jaya Yogyakarta \\ Yogyakarta, Indonesia 55281 \\ Department of Computer Science and \\ Information Technology \\ Kabale University, Kabale, Uganda
}

\author{
Arefin Islam Sourav ${ }^{2}$ \\ Magister Informatika \\ Universitas Atma Jaya Yogyakarta \\ Yogyakarta, Indonesia 55281 \\ Department of Computer Science and \\ Engineering, Daffodil International \\ University, Dhaka, Bangladesh
}

\author{
Djoko Budiyanto Setyohadi ${ }^{3}$ \\ Magister Informatika \\ Universitas Atma Jaya Yogyakarta \\ Yogyakarta, Indonesia 55281
}

\begin{abstract}
Online shopping continues to simplify people's way of life in the present world. People no longer need to physically visit stores to buy items for home use or other purposes. This can be done online using mobile applications to order for preferred items, which can be delivered in return. However, the increase in the features of mobile applications and mobile devices makes usability testing a necessary aspect in today's advancement of technology. This paper uses an experiment-based usability testing evaluation on Lazada Indonesia mobile application to understand four usability factors, namely, ease of use, efficiency, functionality, and satisfaction. The test was performed using 40 participants and all were students from Universitas Atma Jaya Yogyakarta, Universitas Gadjah Mada, and Universitas Sanata Dharma. These performed 6 tasks on the mobile application and later answered a questionnaire to capture their views concerning the usability of the mobile application. The results were analyzed using SPSS software and descriptive statistics were displayed using standard deviation and arithmetic means. The results from the evaluation showed that the mobile application is easy to use, efficient, and has good functionality. However, some issues were mentioned by participants which indicated that users were not fully satisfied with the mobile application. Therefore, this calls for designers to consider these usability issues to increase user satisfaction.
\end{abstract}

Keywords-Usability; usability testing; mobile commerce; mobile application

\section{INTRODUCTION}

Currently, mobile commerce has changed the nature of business worldwide. Mobile commerce can be defined as the act of conducting transactions of goods and services of any monetary value [1], through mobile wireless devices such as smartphones and tablets. With mobile commerce, products can be searched and purchased online by consumers [2], anywhere through internet-enabled wireless devices, without any worry or need to use other devices like laptops. This activity has stimulated the growth rate of the production of mobile applications in app stores. These applications play a big role in the lives of users and have led to the rapid development of the world thus making the world a better place every day. They can be used for several purposes such as online shopping [3],[4], marketing and product distribution [5],[6], delivering and easing Health services [7],[8],[9], monitoring and compiling records, playing games, exercising and home therapy [10], connecting with friends [11], photography, medical support and interactions [12], disaster management [13], accessing educational information by students [14], and so many others. However, because several programmers are coming up with new applications every day, this calls for extra attention to the users, as well as to the developers to ensure that these applications truly perform the roles they are meant for or else it will be a waste of time. Therefore, developers must develop applications of quality and go ahead to prove that these applications play their roles to catch up with the rising market, and this can only be done through usability testing. One of the important factors that give a mobile application quality is its usability. If the usability of the app is complex, then this brings down its quality. Developers should always consider several factors before developing a mobile application and ensure that the application suits the purpose it is meant for. Design constraints such as personalization, data entry models, freedom to navigate should all be considered to give the users satisfaction. In addition to that, applications that deal well with information overload should be considered as it is an important factor that greatly troubles online shoppers nowadays [15]. Usability according to users simply deals with ease of use of the application, the efficiency of the application, effectiveness, and satisfaction of users [16].

Some applications make users frustrated while using them, they are not enjoyable, others do not give users a chance to navigate freely because they have a lot of restrictions, others are very difficult to use, and some also require a lot of strength or thinking to be used by the user. This leaves the users disappointed and unsatisfied with some of the mobile applications, yet they could be important to them. This makes usability testing a vulnerable aspect of mobile application development. Therefore, developers need to carry out usability tests on the users, to understand the effectiveness, ease of use, the efficiency of the applications, and find out if the users are satisfied with the mobile application and their features. This helps developers to improve their designs and thus achieving higher market and competency. In e-commerce business activities, consumers must get and understand information on mobile apps first, before they carry out online purchases. This, therefore, requires application designs that are satisfactory to the users to help them find convenient information faster. The kind of process needs the ease of use of mobile apps in e- 
commerce activities [17]. Users will always stop using any mobile application if it doesn't show its major business intentions and doesn't pay attention to consumer needs. This is because of the absence of all this makes online shopping difficult and uncomfortable for consumers. In the end, consumers will always be attracted by other mobile applications whose human-computer interaction is friendly and attractive. This, therefore [17], makes evaluating usability especially the "ease of use" point very necessary.

Online shopping today continues to ease ways of doing business to the business sector worldwide. With improved technology today, e-commerce has truly shown a big impact and rise through the improvement of online trade since the 1990s. Moreover the trade has now spread to all consumers and sellers both locally and internationally around the globe. People can sell their commodities while in rural areas to people in urban areas, and vice versa just easily through the internet.

Indonesia currently greatly supports online platforms to buy and sell commodities. There are several platforms used in Indonesia such as Lazada Indonesia, Shopee, Tokopedia, Amazon and so many others. The use of mobile smartphones for mobile shopping in Indonesia is increasing due to the rapid growth of the use and access to the internet. In 2017 [18], the number of internet users in Indonesia was reported to rise to 143 million of the total population. This means that the highest number of Indonesians (more than 50\%) possess smartphones [19]. Lazada is an e-commerce website that was launched in March 2012 in Indonesia, Malaysia, the Philippines, Thailand, and Vietnam, all in south-east Asia.

Lazada Indonesia is a very popular e-commerce site in Indonesia that began in 2012. It is one of the fastest-growing online shopping platforms in Indonesia. People use the application to buy and sell several types of products, ranging from home decor, beauty products, elegant products, to health products. This is simply done by accessing the site and application of Lazada. The application is supported by various payment modes including "cash-on-delivery" the most preferred payment mode which makes it simpler for all Indonesian consumers to get all items they order. In the year 2014, Lazada was ranked as the highest visited site in Indonesia. This study concentrated on the Lazada Indonesia application for mobile phones. The objective of this study is to evaluate the usability of the Lazada Indonesia mobile application.

In mobile commerce, users usually experience problems with using online shopping mobile applications. While these problems may result from a lack of experience in using the mobile application, other issues may result due to the poor performance of the mobile application. This study, therefore, aims to understand the performance and issues faced by Lazada Indonesia mobile application users. This will help to fulfill the gaps of usability issues facing users by providing designers with the required information concerning usability challenges from users. This will be done by carrying out a usability test on the mobile application to understand the performance of its features and options used by its users to attain services offered by the mobile application. Four usability aspects i.e., efficiency, functionality, effectiveness, and satisfaction are tested. Understanding the existing issues experienced by users will help Lazada mobile application designers to maintain their strengths and improve the weaknesses of the mobile application following the results from the usability test performed in this study. Filling this gap of usability issues faced by Lazada Indonesia mobile application users will promote its good usability and thus increase user satisfaction of the mobile application.

\section{LITERATURE REVIEW}

\section{A. Smartphones and Mobile Shopping}

Presently, the use of mobile smartphones and internet penetration has increased compared to ancient times. In many countries, more than $50 \%$ of people who own phones possess smartphones and this has made mobile phones the quickest channel for mobile commerce around the world. Consumers use mobile commerce for specific transactions such as ordering for mobile fast foods [20], mobile transport [21], mobile banking [22], mobile payment [23], mobile learning [24], and mobile health [25]. Some researchers claim that mobile commerce and its applications [26] are a rising area as researchers continue to show their interest in this field for research. With the evolution of smartphones, the traditional web-based mobile commerce continues to be replaced by mobile shopping applications [27]. Since carrying out mobile commerce transactions requires the practitioner to own a smartphone [28], mobile online stores theoretically support multiple shopping activities to take place such as searching for information and buying products [29]. However, Sometimes mobile users encounter challenges compared to users shopping using personal computers [30]. The two searches are different in behavior. In some instances, the users may encounter increased costs due to smaller screens of mobile devices and encounter unclear interfaces. However, mobile phones continue to be preferred since they are portable, that is; sellers and buyers can perform business transactions and carry out advertisements at anytime and anywhere [30], and users can have a variety of mobile applications [19]. In addition to that, other users prefer smartphones to view images of commodities displayed in online shops, perform shopping via social media platforms such as Facebook and Instagram [31], as well as listen to music and watch videos [32]. Thus, the popularity of mobile commerce continues to bring a positive impact on society as well as to the business world.

Usually, mobile applications are so significant to users as they are designed by companies to widen their businesses using mobile platforms [33], therefore, most mobile applications are usually mobile versions of online websites. The existence of mobile smartphones provides an alternative channel of doing shopping activities, following offline and online channels. Engaging mobile applications to do mobile shopping is time convenient and since users are usually directly in control, it reduces stress and saves time that would be used moving to shops physically and reduces costs. In addition to that, some retailers can also provide their customers with access to virtual stores [34], which can be useful to consumers to locate and purchase commodities.

However, the increase in the behavior of mobile shopping greatly depends on the experience of the user. As the users' 
experience to use mobile applications increases, the more the online shoppers install more applications. The good usability of any mobile application makes it enjoyable and completely brings reduced irritation while using the mobile application [35]. This is the reason as to why when smartphone owners get more experience of using smartphones [33], they usually tend to possess a higher number of mobile shopping apps. One of the significant quality attributes of a mobile application is the ease of use and freedom of navigation which helps and encourages electronic commerce retailers to carry out their operations effectively [12].

\section{B. Usability and Usability Testing}

Usability can be defined as the ability of the user to be able to interact with the system and perform certain tasks. Usability appears among the key concepts of human-computer interaction which are all covered under the concept of usability engineering. Usability engineering deals with aspects of user interactive experience [17], such as game usability, web usability, and mobile usability. Currently, several researchers have carried out researches about the ease of use of mobile applications. However, the activity of online shopping using mobile applications can only be successful if customers achieve adequate satisfaction. Therefore, usability evaluation in e-commerce becomes a very necessary process to ensure acceptability, ease of use, effective and efficient mobile applications and acts as a significant reference for developers seeking advice for design and feature improvements [36]. In application development, usability evaluation helps in raising the profits, improving designs, and reaching the exact users' expectations. Developers need to aim at producing the best and suitable designs on the market [37], and this can help them to achieve the goal of usability evaluation.

Testing the usability of applications is a crucial activity in the application development life cycle. It confirms the quality as well as the usefulness of the effort applied in developing the mobile application [37]. Several usability evaluations usually require to be carried out on all products, be it commodities, before they are released to exist on the market. This helps to curb down the disappointment and loss of customers in case of any usability issues application, which would exist in the real application designed. The increased use of the internet and the activity of usability testing gives more opportunities to designers to identify issues via usability testing [38], and thus makes the use of mobile applications and mobile devices/gadgets more inherent in our daily lives. Usability Evaluation is based on various activities such as planning the tasks, identifying the evaluation methods, choosing participants, and carrying out the task, analyzing, and recommending the results. Generally, usability testing of mobile applications continues to show its significance at a high rate today. According to some studies, [39][40], some designers have designed and tested the usability of different mobile applications.

\section{Methodology}

In this study, the researchers followed a five-step procedure to carry out usability testing, namely; planning, choosing participants, performing the usability test, analyzing results from the test, and finally documenting the results. This study invited $40(100 \%)$ participants who participated willingly and helped researchers to evaluate the usability of the Lazada Indonesia mobile application. Of the 40 participants, 30 were females $(75 \%)$, and $10(25 \%)$ were males. The participants were all students from universities of Atma Jaya, Gadjah Mada, and Sanata Dharma. All the 40 participants were between the ages of 20 to 35 . However, 12 (30\%) of the participants were in the age category of 20-25 while all the rest 28 (70\%) participants were between the ages of 25-35.

Among the participants, $30(75 \%)$ were master's degree students, $6(15 \%)$ were bachelor's degree students and $4(10 \%)$ were Ph.D. students. All the participants in the study had a clear knowledge of computer operation and android smartphones. However, not all of them were familiar with the operation of the Lazada mobile application. The participants were graded into three main categories of users, i.e. novice/ beginner users, intermediate users, and expert/ experienced users of the application. Out of the total number of participants in the evaluation test, $4(10 \%)$ were novices/ beginner users, 8 $(20 \%)$ were intermediate users and 28 (70\%) were experts/experienced users.

The novices/ beginner users owned smartphones in their daily lives, but they had never installed Lazada Indonesia mobile application. Therefore, these users had never interacted with the mobile application before. The intermediate users had had the Lazada application in their smartphones for not more than 3 months before the test was carried out but had not interacted enough with the mobile application. Each of the intermediate users had at least ever ordered one item from Lazada online shopping, but not more than two items. Expert/ experienced users confessed they had good knowledge about the mobile application and had fully interacted with it for at least 2 or more years. These users knew about online shopping and each of the 28 expert users had ever bought more than 5 items using the Lazada Indonesia mobile application.

The test was carried out at Mrican Residence, in one big free room which was close to the hostels in which all the participants lived. The residence had a very clear and quiet environment and that is why it was chosen to make the participants comfortable first. All participants were asked to carry out the task while seated so that the researchers would learn clearly what they were doing. A questionnaire was distributed to each participant after the test to elicit the participants' perceptions on the usability of Lazada's mobile application's interface. Finally, after conducting the study, SPSS software was used by the researchers for data analysis. The data was illustrated in the form of a mean and standard deviation per item.

\section{A. Tools used for the Experiment}

To carry out this experiment/test, there are several necessary and useful tools that the researchers used in the usability evaluation process. Since the participants were 40 in number, the test was carried out using android smartphones that were owned by each of the participants. The phone brands included Samsung, iPhone, Oppo, and Vivo. Also, A digital video camera (16MP High definition Digital video Camcorder 1080p) was used to record the participants' activities and take their pictures. Another iPhone camera on the researcher's 
mobile phone was used to move around the participants to watch their attitude and reactions while they carried out the given task on the Lazada mobile application. To limit the time for every single task, a stopwatch digital professional LCD was employed. All the 40 participants were provided with a set of test task/scenario that was to be performed (40 sets of test tasks). A set of questionnaires (after-task questionnaire) for each participant was also prepared to be answered at the end of the practical session. The Questionnaire contained demographic part and usability questions. Each usability aspect had four usability questions required to be answered. These questions would help the researchers to evaluate the four intended usability aspects in the study. The statements about the 'ease of use' aspect required the users to answer whether it was easy for them to search items, interact with the interface, whether the mobile application was confusing to them, and whether it was easy for them to locate the search box. On the hand of the 'efficiency aspect', the researchers needed to know whether it did not require much thought, and time for the users to attempt the task, whether they did not get confused about the task, and also to know if they needed extra time to accomplish the task. To consider the 'functionality' of the mobile application, the researchers sought to know from the users whether it was easy for them to navigate through the mobile application as they carried out the task, whether the features of the application were clear and understandable, whether the steps of making a purchase were easy and fast and lastly, whether the application features were responding fast and clearly. Moreso, to prove 'user satisfaction' of the mobile application, the researchers through the questionnaire asked the participants whether carrying out the transaction was satisfying and clear with feedback, whether the users were satisfied with the features and looks of the mobile application, whether they felt comfortable while they used the mobile application, and finally whether they had fun and freedom with the mobile application as they carried out the task. All questions on each aspect were to be answered based on the 5 Likert Scale. i.e., Strong disagree, disagree, Less Agree, Agree and Strong Agree.

The whole test session started with a briefing and a thorough checking by researchers to ensure all participants had a clear and functioning version of Lazada mobile application. For the novice/beginner users who did not have the application, the Lazada application was installed and tested by the researchers on their android phones before the test session started. To ensure a smooth activity, the researchers decided to first carry out a quick pilot study before the participants began attempting the task. This was to ensure that the time given to the participants would be enough for them to carry out the scenarios provided for usability testing, as well as answering the post-task questionnaire. After carrying out the pilot study, the participants were then briefed about the time limit and set to begin performing the task. Two moderators conducted the study to ensure the smooth running of the study and do a proper recording with a camera to capture participants' attitudes.

\section{B. Test Description/ Task Scenarios}

In this experiment, the researchers prepared the task scenarios that were to be carried out by the users/ participants.
The participants were asked to carry out the following six task scenarios on the Lazada mobile application: (1) Search for an iPhone (iPhone 11 pro max) using the search box and add it to the trolley. (2) Return to the home page. Go to the trolley and find the product that was added and buy it using the "pay on delivery" payment option. (3) Search any product of choice and order it using the bank transfer (BCA) payment method, then after completing the process, cancel the order. (4) Search for any 2 household items such as (lunch boxes) of different colors and add each of them to the trolley. (5) Go to the trolley and order for the two lunch boxes at once. (6) Go to the trolley and delete all the items that were added in that task session. The mentioned were the six task scenarios that were to be attempted by the participants.

The test was conducted under specific procedures. Since the participants were many, to effectively carry out the usability evaluation test, the researchers divided them into four groups (A, B, C, D). Each group contained 10 participants. These groups were to participate in the experiment, one group after the other. Choosing which participants to join groups was done randomly by the test moderators. There were no special criteria followed in forming the four groups. After informing each participant to which group they belonged, the place was arranged and participants were tested beginning with group A. Ensuring that the participants were comfortable and ready for the test, each group at a time was briefed and let to begin the test while they were being recorded.

Following the timer after carrying out the task scenarios, participants were asked to answer the questionnaire to help the researchers evaluate the usability of the mobile application. The recording was then stopped, questionnaires were collected from participants and moderators thanked the participants, sent them off, and called for the next group to repeat the exercise until Group D was done, and the exercise finished. The results were later analyzed using SPSS and descriptive statistics such as mean and frequency distribution were used to display and present results of the study.

\section{RESUlt AND Discussion}

The usability evaluation test of this study was purposed to understand the performance and know the challenges faced by Lazada Indonesia mobile application users, as well as to finally know whether the users were satisfied with the mobile application. The test was carried out on four desired usability factors about Lazada mobile application i.e. (1) ease of use of the mobile application; (2) efficiency of the mobile application; (3) functionality of the mobile application and finally, (4) satisfaction attained by users of Lazada mobile application. This section defines the results of the study that were attained from the experiment/ test. The rating scale of the tested factors is also included. Apart from the observation that was done by the moderators, the data analysis greatly considered the answers of the participants since they were the people that were directly involved in the interaction with the mobile application. Therefore, it was considered important to consider their feelings about the usability nature of the mobile application. This is therefore the reason why the researchers mainly relied on the questionnaire answers and comments to make the result of this study. 
Tables I to IV were computed from compiling the responses from the questions that were asked about the four aspects of the mobile application, compiled in the post-task questionnaire. Table $\mathrm{V}$ displays the rating scale. The questionnaire contained four questions for each of the researched usability factors of the mobile application which were to be answered by each of the 40 participants. The participants' answers were given based on the 5 Likert Scale. These were represented by 1,2,3,4 and 5 in SPSS to obtain the mean and standard deviation. Next is a summary and explanation of the results, ranging from ease of use, efficiency, functionality, and satisfaction of users with Lazada Indonesia mobile application.

TABLE I. EASE OF USE (EU)

\begin{tabular}{|c|c|c|c|c|c|c|c|c|c|c|}
\hline \multirow{2}{*}{ Item } & \multirow{2}{*}{$\mathbf{N}$} & \multirow{2}{*}{ Min } & \multirow{2}{*}{ Max } & \multirow{2}{*}{ Mean } & \multirow{2}{*}{ St. Deviation } & \multicolumn{5}{|l|}{ Likert Scale } \\
\hline & & & & & & Strongly Disagree & Disagree & Less Agree & Agree & Strongly Agree \\
\hline EU1 & 40 & 1 & 5 & 4.33 & 0.944 & 0 & 2 & 1 & 15 & 22 \\
\hline EU2 & 40 & 1 & 5 & 4.43 & 0.931 & 1 & 1 & 3 & 10 & 25 \\
\hline EU3 & 40 & 1 & 5 & 4.55 & 0.904 & 0 & 1 & 2 & 7 & 30 \\
\hline EU4 & 40 & 1 & 5 & 4.68 & 0.859 & 0 & 1 & 1 & 4 & 34 \\
\hline
\end{tabular}

TABLE II. EFFICIENCY (EF)

\begin{tabular}{|c|c|c|c|c|c|c|c|c|c|c|}
\hline \multirow{2}{*}{ Item } & \multirow{2}{*}{$\mathbf{N}$} & \multirow{2}{*}{ Min } & \multirow{2}{*}{$\operatorname{Max}$} & \multirow{2}{*}{ Mean } & \multirow{2}{*}{ St. Deviation } & \multicolumn{5}{|l|}{ Likert Scale } \\
\hline & & & & & & Strongly Disagree & Disagree & Less Agree & Agree & Strongly Agree \\
\hline Ef1 & 40 & 1 & 5 & 4.52 & 0.960 & 0 & 2 & 1 & 7 & 30 \\
\hline Ef2 & 40 & 1 & 5 & 4.38 & 1.055 & 1 & 1 & 2 & 10 & 26 \\
\hline Ef3 & 40 & 1 & 5 & 4.48 & 0.987 & 0 & 2 & 2 & 7 & 29 \\
\hline Ef4 & 40 & 1 & 5 & 4.60 & 0.871 & 0 & 1 & 1 & 7 & 31 \\
\hline
\end{tabular}

TABLE III. FUNCTIONALITY (F)

\begin{tabular}{|c|c|c|c|c|c|c|c|c|c|c|}
\hline \multirow{2}{*}{ Item } & \multirow{2}{*}{$\mathbf{N}$} & \multirow{2}{*}{ Min } & \multirow{2}{*}{ Max } & \multirow{2}{*}{ Mean } & \multirow{2}{*}{ St. Deviation } & \multicolumn{5}{|l|}{ Likert Scale } \\
\hline & & & & & & Strongly Disagree & Disagree & Less Agree & Agree & Strongly Agree \\
\hline F1 & 40 & 3 & 5 & 4.78 & 0.480 & 0 & 0 & 1 & 7 & 32 \\
\hline F2 & 40 & 2 & 5 & 4.40 & 0.744 & 0 & 1 & 3 & 15 & 21 \\
\hline $\mathrm{F} 3$ & 40 & 2 & 5 & 4.52 & 0.679 & 0 & 1 & 1 & 14 & 24 \\
\hline $\mathrm{F} 4$ & 40 & 1 & 5 & 4.28 & 0.847 & 0 & 1 & 1 & 20 & 18 \\
\hline
\end{tabular}

TABLE IV. SATISFACTION (S)

\begin{tabular}{|c|c|c|c|c|c|c|c|c|c|c|}
\hline \multirow{2}{*}{ Item } & \multirow{2}{*}{$\mathbf{N}$} & \multirow{2}{*}{ Min } & \multirow{2}{*}{ Max } & \multirow{2}{*}{ Mean } & \multirow{2}{*}{ St. Deviation } & \multicolumn{5}{|l|}{ Likert Scale } \\
\hline & & & & & & Strongly Disagree & Disagree & Less Agree & Agree & Strongly Agree \\
\hline S1 & 40 & 1 & 5 & 4.60 & 0.900 & 0 & 0 & 2 & 6 & 32 \\
\hline S2 & 40 & 4 & 5 & 4.58 & 0.501 & 0 & 0 & 0 & 17 & 23 \\
\hline S3 & 40 & 3 & 5 & 4.48 & 0.554 & 0 & 0 & 1 & 19 & 20 \\
\hline S4 & 40 & 3 & 5 & 4.73 & 0.506 & 0 & 0 & 1 & 9 & 30 \\
\hline
\end{tabular}

TABLE V. RATING OF LAZADA MobILE APPLICATION

\begin{tabular}{|l|l|l|}
\hline Scale & Weighted Mean Range & Grading of Usability aspects \\
\hline 5 & $4.51-5.00$ & Very High \\
\hline 4 & $3.51-4.50$ & High \\
\hline 3 & $2.51-3.50$ & Medium \\
\hline 2 & $1.51-2.50$ & Less \\
\hline 1 & $1.00-1.50$ & Least \\
\hline
\end{tabular}




\section{A. Ease of use of Lazada Mobile Application}

Table I contains the descriptive statistics for ease of use of Lazada Indonesia mobile application and each item is indicated by the mean and standard deviation. The results obtained from the post-test questionnaire answered by the participants after they completed the exercise indicated that most of the participants strongly agreed that the application was very easy for them to use during the evaluation test that they were given by the moderators. Ease of use is very important in a way that if it deteriorates, the usefulness of the application also deteriorates and vice versa [41]. The responses from the "ease of use" questions were graded with a mean of 4.68 out of 5.00, and a standard deviation of 0.859 . This is graded as "Very High" according to the rating scale in Table V.

The highest percentage of participants confessed that they did not find complications while they searched for the items, they easily interacted with the interface without any confusion. Only a few participants less agreed and this was because they were novice users, so they had never interacted with the Lazada mobile application before. The results portray that Lazada mobile application has a good ease of use design to the users. Usability is greatly associated with the ease of use of a mobile application, therefore, mobile application designers have to focus on the usability aspect as this can even affect the market of mobile devices [42]. If users cannot interact with any mobile application, the application's value degrades and will have fewer users. Basing on the results of this aspect, Mobile users are recommended to buy devices and install applications that are simple for them to use [43]. Mobile devices like smartphones and tablets contain applications that are intended for end-users as their main feature [44] thus, developers must take care of Human-Computer Interaction (HCI) aspects.

\section{B. Efficiency of Lazada Mobile Application}

The descriptive statistics for the efficiency of the use of Lazada mobile applications are displayed in table two. The efficiency of Lazada mobile application was graded with a mean of 4.60 out of 5.00, and a standard deviation of 0.871 . According to Table V, this is also perceived as "Very High", indicating that the mobile application is very efficient in use. Similarly, most participants in the study agreed that Lazada mobile application is efficient to use. The highest number strongly agreed that the application did not require much thought from them to complete the task, they did not spend a lot of time on performing the task, and they were not confused on how to carry out the task. Most of them were able to complete the task successfully and confessed in the post-test completed questionnaire that they did not require extra time. Only a few novice participants found some issues because they were new users, however, they were also quick at understanding when they sought help. They were able to complete the task although with just a little help by explanation.

The answers from the questionnaire and result compilation show that the application is efficient while the users are using it. Without a doubt, one of the most important factors to be considered by designers is the efficiency of the mobile application, as it also allows users to utilize the energy of their mobile devices [45]. Therefore, designers should ensure that users take less time to complete their goals while using an application. The efficiency of the application means that it is clearly functioning [46], to carry out its purpose using minimal resources and thus finally bring satisfaction to users. This becomes the only reason as to why the rating of any product greatly depends on efficiency [47], because high efficiency attracts high ratings as it enhances satisfaction and vice versa.

\section{Functionality of Lazada Mobile Application}

Table III illustrates the functionality of Lazada mobile application according to the test that was carried out in this study. The functionality aspect attained a mean of 4.78 out of 5.00 and a standard deviation of 0.480 . This is also graded as "Very High" according to the grading scale in Table V. The result, therefore, indicates that most of the participants agreed that Lazada mobile application has good functionality. In Table III, the mean and standard deviation of each item are shown and the result implies that the functionality of the interface was pleasing to the participants.

Most of them strongly agreed to statements in the questionnaire such as "the application is user friendly and allows free navigation of the user, "the features on the site are clear and understandable", "The application features were fast to respond", and the steps for making the purchase were not complex to perform. Users were seen to prefer the search button because their feedbacks were returning fast. The more the features respond fast the more the users enjoy the functionality of the application and thus attracting satisfaction in the long run [48]. Following the results, the functionality of a mobile application is very important as it attracts users to continue using the application [49]. If the functionality of the system is not nice, such as doesn't give free navigation to the users, users will leave frustrated and will not use the application again as it won't let them achieve their goals [50]. Poor functionality leaves users dissatisfied, and this may finally lead to the disloyalty of the application.

\section{User Satisfaction with Lazada Mobile Application}

In the last part of the activity, the researchers needed to know how much the users were satisfied with the mobile application. Table IV shows the descriptive statistics of user satisfaction of participants from using the Lazada Indonesia mobile application. The mean and standard deviation for each item are shown in the table.

Although most participants including new users agreed that Lazada mobile application and its features were an enjoyable application to use even for the novice users, they claimed they were not fully satisfied with the mobile application. According to the results, Lazada mobile application gives comfort to its users but not complete satisfaction [51]. Accumulated satisfaction can be attained by building the customers' trust in the mobile application [52], as this further greatly influences the intended purchase of users. Based on the results, it can be argued that satisfaction is a very important aspect of usability evaluation as it brings users positive thoughts and attraction to the mobile application. Satisfaction does not only depend on the mobile application itself but also depends on the mobile application store [53], i.e. service providers. Satisfaction gives users a feeling of fun and comfort while using the mobile application. Perceived satisfaction is the only key factor to 
entice mobile users to engage in using online shopping mobile applications [54]. This is because satisfaction makes users develop a positive attitude and trust towards products sold and positive word-of-mouth that increases product loyalty and creates uniqueness in the mobile application.

In this study as we tested user satisfaction, participants pointed out some issues, which indicated that users were not fully satisfied with the operation of the mobile application. Novice users as well found some usability complications in carrying out the task such as locating the trolley while they were on the main page. In addition to that, the intermediate users had difficulties in making transactions using the bank transfer method, as it involved extensive steps. The other challenging issue was a deep understanding of the language by foreign participants since Lazada Indonesia uses Bahasa Indonesia. In addition to the mentioned issues, some experienced participants complained that the android application was slow in loading and displaying the trolley, and even when displayed, it required much time lag to perform any action where almost $90 \%$ of the time error message prompts displayed.

Other users complained that during their search of items as they performed the task, a lot of irrelevant items appeared in their search which was unpleasing. "It required a lot of time to locate the wanted item", the users confessed. And lastly, the participants complained about the second to last task they were asked to perform. They complained that it was not possible to check out the items in the trolley using the "pay on delivery" if items that could pay on delivery were checked out with items that were not allowed to pay on delivery. Users suggested that it would be better if items allowed to pay on delivery would be differentiated from items that are not allowed to pay on delivery if the user tried to check out, rather than denying the whole payment option of "pay on delivery". All these complaints confirmed to the researchers that users were not fully satisfied with the mobile application, thus designers need to attend to the issues first to increase user satisfaction.

\section{CONCLUSION}

This study was intended to understand the performance and issues facing Lazada Indonesia mobile application users through carrying out a usability test on the mobile application by further considering four usability aspects i.e. ease of use, efficiency, functionality, and satisfaction attained by users from using the mobile application. Overall, from the results obtained from data analysis, the performance of the mobile application proved good to most of the participants of the study. The mobile application showed good ease of use, adequate efficiency, and effectiveness, but did not provide complete satisfaction to the users.

Based on the results, users were not fully satisfied with the mobile application due to the following usability issues that were mentioned by some participants, i.e. (1) language barrier experienced by foreign users, (2) Slowness of the mobile application in loading the trolley, (3) Appearing of irrelevant items during product search by users, and (4) Failure to separate items that allow COD from those which don't allow COD during the checkout process. In conclusion, therefore, the designers of Lazada Indonesia mobile application need to improve their design by solving the usability challenges experienced by some users, which in the actual sense could make a large number if considered out of the whole total population of Lazada Indonesia mobile application users. Solving users' complaints can make the application more marketable and trustworthy, and overall increase user satisfaction.

\section{LIMITATIONS AND FUTURE WORK}

Like any other researches, this study encountered some limitations during the experiment. The study used only 40 participants for the experiment since it was not easy to gather many people as this study was carried out during the COVID19 pandemic. Therefore, this limited the expected sample size. The researchers hope that the results would have been much better with bigger sample size. Since this study only concentrated on Lazada Indonesia mobile shopping application, future studies should consider testing the users of the Lazada Indonesia desktop application because the two are different in their nature of search. Furthermore, this test was carried out by mixing the users of different experiences of using the mobile application. Future research can be carried out by grouping and testing the users differently according to their levels of experience to understand the issues experienced by users at different levels of experience. This will help the designers to understand which usability problems to solve first and at what stage of using the application these usability problems are encountered, thus providing quick solutions to challenges and increase the satisfaction of Lazada Indonesia mobile application users.

\section{ACKNOWLEDGMENT}

We thank the participants of the study, the department of Informatika Universitas Atma Jaya, and KNB scholarship for supporting this research.

\section{REFERENCES}

[1] N. Shaw and K. Sergueeva, "The non-monetary benefits of mobile commerce: Extending UTAUT2 with perceived value," Int. J. Inf. Manage., vol. 45, no. October 2018, pp. 44-55, 2019, doi: 10.1016/j.ijinfomgt.2018.10.024.

[2] E. Marinao-Artigas and K. Barajas-Portas, "Precedents of the satisfaction of mobile shoppers. A cross-country analysis," Electron. Commer. Res. Appl., vol. 39, p. 100919, 2020, doi: 10.1016/j.elerap.2019.100919.

[3] T. Natarajan, S. A. Balasubramanian, and D. L. Kasilingam, "Understanding the intention to use mobile shopping applications and its in fl uence on price sensitivity," J. Retail. Consum. Serv., vol. 37, no. March, pp. 8-22, 2017, doi: 10.1016/j.jretconser.2017.02.010.

[4] G. McLean and A. Wilson, "Shopping in the digital world: Examining customer engagement through augmented reality mobile applications," Comput. Human Behav., vol. 101, no. July, pp. 210-224, 2019, doi: 10.1016/j.chb.2019.07.002.

[5] S. Nuanmeesri, "Mobile application for the purpose of marketing, product distribution and location-based logistics for elderly farmers," Appl. Comput. Informatics, 2019, doi: 10.1016/j.aci.2019.11.001.

[6] R. Pitakaso, K. Sethanan, and T. Jamrus, "Hybrid PSO and ALNS algorithm for software and mobile application for transportation in ice manufacturing industry 3.5," Comput. Ind. Eng., vol. 144, p. 106461, 2020, doi: 10.1016/j.cie.2020.106461.

[7] S. Yoo et al., "Developing a mobile epilepsy management application integrated with an electronic health record for effective seizure management," Int. J. Med. Inform., vol. 134, p. 104051, 2020, doi: 10.1016/j.jimedinf.2019.104051. 
[8] R. Paramastri et al., "The use of mobile applicatiosn to improve nutrition behaviour: A systematic review," Comput. Methods Programs Biomed., vol. 192, p. 105459, 2020, doi: 10.1016/j.cmpb.2020.105459.

[9] P. Piran et al., "Medical Mobile Applications for Stroke Survivors and Caregivers," J. Stroke Cerebrovasc. Dis., vol. 28, no. 11, p. 104318, 2019 , doi: 10.1016/j.jstrokecerebrovasdis.2019.104318.

[10] K. Valdes, E. Gendernalik, J. Hauser, and M. Tipton, "Use of mobile applications in hand therapy," J. Hand Ther., 2020, doi: 10.1016/j.jht.2019.10.003

[11] M. Anshari and Y. Alas, "Smartphones habits, necessities, and big data challenges," J. High Technol. Manag. Res., vol. 26, no. 2, pp. 177-185, 2015, doi: 10.1016/j.hitech.2015.09.005.

[12] C. Campbell-Grossman, D. B. Hudson, K. M. Hanna, B. Ramamurthy, and V. Sivadasan, "Ease of Use and Acceptability of a Smartphone App for Young, Low-Income Mothers," J. Technol. Behav. Sci., vol. 3, no. 1, pp. 5-11, 2018, doi: 10.1007/s41347-017-0031-5.

[13] V. Sukhwani and R. Shaw, "Operationalizing crowdsourcing through mobile applications for disaster management in India," Prog. Disaster Sci., vol. 5, p. 100052, 2020, doi: 10.1016/j.pdisas.2019.100052.

[14] A. Razzaq, Y. T. Samiha, and M. Anshari, "Smartphone habits and behaviors in supporting students self-efficacy," Int. J. Emerg. Technol. Learn., vol. 13, no. 2, pp. 94-109, 2018, doi: 10.3991/ijet.v13i02.7685.

[15] J. V. Chen, A. Tran, and T. Nguyen, "Computers in Human Behavior Understanding the discontinuance behavior of mobile shoppers as a consequence of technostress : An application of the stress-coping theory," Comput. Human Behav., vol. 95, no. January, pp. 83-93, 2019, doi: 10.1016/j.chb.2019.01.022.

[16] S. N. Upadhe, D. D. Shinde, and U. S. Mugale, "Ease of Use Experimentation of Isometric Template," Procedia Manuf., vol. 20, pp. 296-299, 2018, doi: 10.1016/j.promfg.2018.02.044.

[17] X. Li, X. Zhao, W. (Ato) Xu, and W. Pu, "Measuring ease of use of mobile applications in e-commerce retailing from the perspective of consumer online shopping behaviour patterns," J. Retail. Consum. Serv., vol. 55, no. March, p. 102093, 2020, doi: 10.1016/j.jretconser.2020.102093.

[18] F. V. Haucke, "Smartphone-enabled social change: Evidence from the Fairphone case?," J. Clean. Prod., vol. 197, pp. 1719-1730, 2018, doi: 10.1016/j.jclepro.2017.07.014.

[19] A. A. Pinem, A. Yeskafauzan, P. W. Handayani, F. Azzahro, A. N. Hidayanto, and D. Ayuningtyas, "Designing a health referral mobile application for high-mobility end users in Indonesia," Heliyon, vol. 6, no. 1, p. e03174, 2020, doi: 10.1016/j.heliyon.2020.e03174.

[20] U. Akram, A. R. Ansari, G. Fu, and M. Junaid, "Feeling hungry? let's order through mobile! examining the fast food mobile commerce in China," J. Retail. Consum. Serv., vol. 56, no. April, p. 102142, 2020, doi: 10.1016/j.jretconser.2020.102142.

[21] R. Septiani, P. W. Handayani, and F. Azzahro, "Factors that Affecting Behavioral Intention in Online Transportation Service: Case study of GOJEK," Procedia Comput. Sci., vol. 124, pp. 504-512, 2017, doi: 10.1016/j.procs.2017.12.183.

[22] A. Shankar and B. Rishi, "Convenience matter in mobile banking adoption intention?," Australas. Mark. J., no. xxxx, 2020, doi: 10.1016/j.ausmj.2020.06.008.

[23] S. H. Liao and L. L. Yang, "Mobile payment and online to offline retail business models," J. Retail. Consum. Serv., vol. 57, no. 151, p. 102230, 2020, doi: 10.1016/j.jretconser.2020.102230.

[24] D. B. Setyohadi, sri Kusrohmaniah, C. Efrans, T. D. Luciana, and P. S. Bening, "M-Learnıng Interface Design Based On Emotıonal Aspect Analysis," Conf. Pap. Lect. Notes Comput. Sci., vol. 1, no. January, pp. 15-26, 2017, doi: 10.1007/978-3-319-52503-7.

[25] T. Chen, "Assessing factors critical to smart technology applications to mobile health care - the fgm-fahp approach," Heal. Policy Technol., vol. 9, no. 2, pp. 194-203, 2020, doi: 10.1016/j.hlpt.2020.02.005.

[26] J. J. Hew, "Hall of fame for mobile commerce and its applications: A bibliometric evaluation of a decade and a half (2000-2015)," Telemat. Informatics, vol. 34, no. 1, pp. 43-66, 2017, doi: 10.1016/j.tele.2016.04.003.
[27] D. L. Kasilingam, "Understanding the attitude and intention to use smartphone chatbots for shopping," Technol. Soc., p. 101280, 2020, doi: 10.1016/j.techsoc.2020.101280.

[28] A. K. Y. Tang, "A systematic literature review and analysis on mobile apps in m-commerce: Implications for future research," Electron. Commer. Res. Appl., vol. 37, no. February, p. 100885, 2019, doi: 10.1016/j.elerap.2019.100885.

[29] S. Sohn, "A contextual perspective on consumers' perceived usefulness: The case of mobile online shopping," J. Retail. Consum. Serv., vol. 38, no. April, pp. 22-33, 2017, doi: 10.1016/j.jretconser.2017.05.002.

[30] K. Y. Goh, J. Chu, and J. Wu, "Mobile advertising: An empirical study of temporal and spatial differences in search behavior and advertising response," J. Interact. Mark., vol. 30, pp. 34-45, 2015, doi: 10.1016/j.intmar.2014.12.002.

[31] J. Vithayathil, M. Dadgar, and J. K. Osiri, "International Journal of Information Management Social media use and consumer shopping preferences,” Int. J. Inf. Manage., vol. 53, no. October 2019, p. 102117, 2020, doi: 10.1016/j.ijinfomgt.2020.102117.

[32] A. Y. L. Chong, "Mobile commerce usage activities: The roles of demographic and motivation variables," Technol. Forecast. Soc. Change, vol. 80, no. 7, pp. 1350-1359, 2013, doi: 10.1016/j.techfore.2012.12.011.

[33] M. Kim, J. Kim, J. Choi, and M. Trivedi, "Mobile Shopping Through Applications: Understanding Application Possession and Mobile Purchase," J. Interact. Mark., vol. 39, pp. 55-68, 2017, doi: 10.1016/j.intmar.2017.02.001.

[34] E. Pantano, "Innovation drivers in retail industry," Int. J. Inf. Manage., vol. 34, no. 3, pp. 344-350, 2014, doi: 10.1016/j.ijinfomgt.2014.03.002.

[35] Y. Lee and H. Y. Kim, "Consumer need for mobile app atmospherics and its relationships to shopper responses," J. Retail. Consum. Serv., vol. 51, no. June 2017, pp. 437-442, 2019, doi: 10.1016/j.jretconser.2017.10.016.

[36] F. J. Martínez-López, Y. Li, H. Liu, and C. Feng, "Do safe buy buttons and integrated path-to-purchase on social platforms improve users' shopping-related responses?," Electron. Commer. Res. Appl., vol. 39, no. October 2019, p. 100913, 2020, doi: 10.1016/j.elerap.2019.100913.

[37] A. Kaur and K. Kaur, "A COSMIC function points based test effort estimation model for mobile applications," J. King Saud Univ. - Comput. Inf. Sci., no. xxxx, 2019, doi: 10.1016/j.jksuci.2019.03.001.

[38] N. Bento, "Calling for change? Innovation, diffusion, and the energy impacts of global mobile telephony," Energy Res. Soc. Sci., vol. 21, pp. 84-100, 2016, doi: 10.1016/j.erss.2016.06.016.

[39] S. Meedya et al., "Developing and testing a mobile application for breastfeeding support : The Milky Way application," Women and Birth, no. 2019, 2020, doi: 10.1016/j.wombi.2020.02.006.

[40] S. Clavijo-Buendía et al., "Construct validity and test-retest reliability of a free mobile application for spatio-temporal gait analysis in Parkinson's disease patients," Gait Posture, vol. 79, pp. 86-91, 2020, doi: 10.1016/j.gaitpost.2020.04.004.

[41] A. M. Lund, "Measuring usability with the USE questionnaire," Usability interface, vol. 8, no. 2, pp. 3-6, 2001, doi: 10.1177/1078087402250360.

[42] M. A. Uddin, H. Xu, and M. T. Azim, "Factors affecting mobile handset (MH) buying decision: An empirical study," Int. J. Manag. Bus. Res., vol. 5, no. 3, pp. 225-236, 2015.

[43] M. Dunlop and S. Brewster, "The challenge of mobile devices for human computer interaction," Pers. Ubiquitous Comput., vol. 6, no. 4, pp. 235236, 2002, doi: 10.1007/s007790200022.

[44] A. Meneses-Viveros, E. Hernández-Rubio, S. Mendoza, J. Rodríguez, and A. B. Márquez Quintos, "Energy saving strategies in the design of mobile device applications," Sustain. Comput. Informatics Syst., vol. 19, pp. 86-95, 2018, doi: 10.1016/j.suscom.2018.07.011.

[45] K. Yan, J. Tan, and X. Fu, "Improving energy efficiency of mobile devices by characterizing and exploring user behaviors," J. Syst. Archit., vol. 98, no. November 2018, pp. 126-134, 2019, doi: 10.1016/j.sysarc.2019.07.004.

[46] A. Hussain, E. O. C. Mkpojiogu, N. H. Jamaludin, and S. T. L. Moh, "A usability evaluation of Lazada mobile application," AIP Conf. Proc., vol. 1891, no. October, 2017, doi: 10.1063/1.5005392. 
[47] A. Hussain, E. O. C. Mkpojiogu, J. Musa, and S. Mortada, "A user experience evaluation of Amazon Kindle mobile application," AIP Conf. Proc., vol. 1891, 2017, doi: 10.1063/1.5005393.

[48] Z. Mushtaq and A. Wahid, "Inclusion of Functional and Non-Functional Parameters for the Prediction of Overall Efforts of Mobile Applications.," Comput. Stand. Interfaces, vol. 71, p. 103404, 2020, doi: 10.1016/j.csi.2019.103404.

[49] A. J. G. Silvius and C. M. Silvius, "Exploring Functionality of Mobile Applications for Project Management," Procedia Comput. Sci., vol. 64, pp. 343-351, 2015, doi: 10.1016/j.procs.2015.08.498.

[50] M. Rezae, N. Chen, D. McMeekin, T. Tan, A. Krishna, and H. Lee, "The evaluation of a mobile user interface for people on the autism spectrum: An eye movement study," Int. J. Hum. Comput. Stud., vol. 142, no. May, p. 102462 , 2020, doi: 10.1016/j.ijhcs.2020.102462.
[51] A. Hussain, E. O. C. Mkpojiogu, H. Abubakar, and H. M. Hassan, "The usability evaluation of Mudah.my on mobile device," AIP Conf. Proc., vol. 1891, 2017, doi: 10.1063/1.5005391.

[52] W. T. Wang, W. M. Ou, and W. Y. Chen, "The impact of inertia and user satisfaction on the continuance intentions to use mobile communication applications: A mobile service quality perspective," Int. J. Inf. Manage., vol. 44, no. May 2018, pp. 178-193, 2019, doi: 10.1016/j.ijinfomgt.2018.10.011.

[53] J. Song, J. Kim, D. R. Jones, J. Baker, and W. W. Chin, “Application discoverability and user satisfaction in mobile application stores: An environmental psychology perspective," Decis. Support Syst., vol. 59, no. 1, pp. 37-51, 2014, doi: 10.1016/j.dss.2013.10.004.

[54] F. Luna-Perejon et al., "Evaluation of user satisfaction and usability of a mobile app for smoking cessation," Comput. Methods Programs Biomed., vol. 182, p. 105042, 2019, doi: 10.1016/j.cmpb.2019.105042. 